\title{
Seismic Evaluation of Horizontally Curved Bridges Subjected to Near- Field Ground Motions
}

\author{
Mahmood Minavand ${ }^{a}$ \\ Mohsen Ghafory-Ashtiany ${ }^{\mathrm{b} *}$ \\ a Department of Structural Engineering, Science and Research Branch, Islamic Azad University, Tehran, Iran. \\ Email:minavand_m@yahoo.com \\ b Structural Engineering Research Center, International Institute of Earthquake Engineering and Seismology (IIEES), Tehran, Iran. \\ E-mail: ashtiany@iiees.ac.ir \\ * Corresponding author
}

http://dx.doi.org/10.1590/1679-78255438

\begin{abstract}
Horizontally curved bridges have more complex seismic behavior than straight bridges and have been more vulnerable to earthquakes. The present study aimed to evaluate the seismic response of concrete bridges with straight and arched box girder decks in isolated and non-isolated states. The results indicated that increasing the curvature of the non-isolated bridge could increase the irregularity. In addition, increasing the curvature of the deck leads to an increase in shear force, bending moment, and displacement in the piers in the radial direction of the arc, and causes vulnerability of the piers in this direction. Further, in the deck of the bridge, the reduction of the arc radius, especially in the non-isolated bridges, considerably increases the radial shear force, torsion and minor bending moment of the deck. In both isolated and non-isolated cases, the demand in the piers and deck of the bridge under the influence of near-fault ground motions is greater than that of the far-field earthquakes. Seismic isolation results in reducing the force demand in the pier, and the deck of the bridge, leading to a reduction in the force demand rate caused by increasing the central arc angle on the bridge deck.
\end{abstract}

\section{Keywords}

Horizontally Curved Bridge, Near-Fault Ground Motion, Base Isolation, Friction Pendulum Bearing, Deck Curvature.

\section{INTRODUCTION}

As horizontally curved bridges with high-curvature are dynamically considered with geometric irregularity, they have no appropriate seismic response to earthquakes (Soberón and Soberón (2017)). Increasing the deck curvature leads to an increase in the force demand on the bridge deck and piers, which plays a significant role on the seismic vulnerability of the bridges such as the damage caused by the curved spans of Baihua Bridge in the earthquake occurred in 2008 in Wenchuan, China (Han et al. (2009)). Horizontally curved bridges due to structural irregularities and its rigid torsional motions of the deck cause deck to be unseating and pounding in the expansion joints and as a result, suffer severe damage in earthquakes. The radial and tangential displacements of the deck corners plus rotation about the mass center are the most important parameters to the seismic response of these types of bridge. (Amjadian, M. \& Agrawal, A. K. (2016)).

Arched bridges already have been studied by some researchers. In most of the conducted studies, the radius of the arc in plan was considered as the main variable in the behavior of these bridges and the structural response of the bridge was compared in radial and tangential directions. Hosoda et al. (1992) compared the seismic response of a curved bridge in plan with a straight bridge in Japan. The results indicated that the seismic response of the curved 
bridge substructure is higher and lower than the straight bridge in tangential and radial direction, respectively. Mendez \& Hayashikawa (2009) evaluated curved bridges with different arc radii and found that curved bridges have larger uplift forces than straight bridges. Desantiago et al. (2005) reported that the bending moment of the deck of the curved bridges is about $23.5 \%$ higher than the straight ones with equal spans. Tondini and Stojadinovic (2012) considered the radius of the deck curve of the bridge as a variable and conducted static linear, nonlinear dynamic and modal analysis for different types of bridges. The results indicated that the drift along the transverse direction increases in the sharply curved bridge. Also, other parameters can affect the seismic response of curved bridges. Seo and Linzell (2013) performed the sensitivity analysis on some curved bridges in Pennsylvania by comparing their fragility curves in order to evaluate the effect of different parameters on the response of the curved bridges such as the number of spans, span length, deck width, height of the piers, and arc radius of deck. Based on the results, some parameters such as the number of piers and arc radius of the bridge had the most effect on the responses. Furthermore, a decrease in the arc radius leads to an increase in the displacement of the bearings, the ductility demand of the piers and their axial force by $17 \%$ to $22 \%$. The irregularity of the bridges due to the arches in the plan and the height is directly related to the bridges vulnerability level. Comparison of fragility curves shows that the vulnerability of bridge components due to irregularities in the elevation is more than irregularities in the plan (Abbasi et al. (2016)). Combination of several seismic retrofit strategies should be applied to reduce damage and achieve the proper performance level of the horizontally curved bridges (Pahlavan, $\mathrm{H}$ et al. (2015)).

Seismic isolation is a suitable solution to reduce the vulnerability of structures, especially for horizontally curved bridges, and improve their seismic behavior. Seismic isolation bearings with lateral flexibility allow the period shifts to the low-acceleration region of the response spectrum, which reduces the input force to the structure. Furthermore, an increase in the damping results in increasing the input energy dissipation and reducing their vibration amplitude. Ates and Constantinou (2011) studied the seismic response of a concrete bridge with curved deck in plan with box section in two non-isolated and isolated states through the response spectrum analysis by considering the effect of soil-structure interaction (SSI). The results indicated that using seismic isolation reduces the internal forces in the curved bridge, compared to the non-isolated bridges. The maximum displacement of the bearings occurs when the bridge is subjected to the seismic loads in a radial direction. Seismic isolator type can influence the response of curved bridge in plan, and choosing their proper specifications improves the seismic performance of the curved bridges. Giménez et al. (2011) studied the dynamic behavior of curved bridges equipped with seismic isolators such as Lead Rubber Bearing (LRB), Friction Pendulum Bearing (FPB) and High Damping Rubber Bearing (HDRB) with different structural and damping specifications and evaluated the vulnerability of curved bridges in plan due to the deck impact in the expansion joints. Based on the results, the FPB system requires the use of a higher friction coefficient in order to control the deck displacement in such bridges. Regarding the high damping, the curved bridges equipped with HDRB have a good behavior against deck impact damage. Further, by increasing the lead diameter in the LRB, the lateral displacement in the deck of the curved bridge decreases, and the probability of damage caused by impact decreases and dissipates more energy.

The response of structures located near the fault is highly influenced by the characteristics of the ground motion such as fault mechanism, velocity pulse, rupture directivity and fling step due to their proximity to the source of the wave propagation and low attenuation in the seismic waves (Somerville (2002)). These ground motions have long period velocity pulses with large amplitudes in the perpendicular component to the fault, though involving highfrequency content. Therefore, a high amount of energy is suddenly applied to the structure in a short time. In this case, the structure should dissipate the applied energy under a few numbers of plastic cycles. This demand can impact the structures with a limited ductility (Kalkan and Kunnath (2006), Hall et al. (1995)). The period proximity of the structure with one half the periods of the main forward-directivity pulses caused significant amplification in the inelastic response of reinforced concrete curved bridge (Angelidakis et al. (2017)). Numerous researches have been conducted to control the pulse effects of near-fault ground motions on base isolated bridges. Gao et al. (2015) proposed a cablesliding modular expansion joint which significantly decreased the relative peak displacement due to near-fault ground motions. Ghosh et al. (2012) studied the types of seismic isolators in the response of continuously curved bridges in plan under the influence of the near-fault ground motion of Kobe and found that LRB, HDRB and FPB systems could reduce the response of pier displacement and force. Gimenez et al. (2015) studied the curved bridge equipped with seismic isolators under the influence of several near-fault ground motions and concluded that the use of isolators significantly reduces the damage in the piers in these bridges. Kataria \& Jangid (2016) found out that using the hybrid systems, such as the combination of semi-active systems with variable stiffness and LRB, is very effective in improving the seismic behavior of horizontally curved bridges. 
By considering the above-mentioned studies, the present study aimed to evaluate the seismic behavior of horizontally curved bridges with different arc radii. For this purpose, the Sadr Bridge model with box-girder deck located in Tehran was used. The bridge is modeled in non-isolated and seismic isolated states. The nonlinear behavior of the materials in the piers, decks and seismic isolators was taken into consideration. Then, the near-fault and far-fault ground motions were applied to the bridge in a longitudinal direction and nonlinear time history analysis was done for each of them. The results indicated that an increase in the deck curvature results in reducing the tangential shear force and drift in the bridge piers and increasing the radial shear force and drift in the piers significantly. In both isolated and non-isolated structures, the shear force of the piers and consequently its bending moments were influenced by the near-fault earthquake more than that of far-field earthquakes. In the force-displacement curves of the pier, decreasing the arc radius of the deck led to plastic deformation in the radial direction of the pier. Furthermore, an increase in the curvature resulted in increasing the forces and bending moments in the deck of the non-isolated bridge. In addition, radial shear force, torsion and minor bending moment of the deck section of the non-isolated bridge increased significantly. Seismic isolators reduced the difference between the bending moments and shear force values of the deck due to a decrease in the arc radius of the deck and bringing them closer to the straight bridge.

\section{BRIDGE INTRODUCTION AND MODELING}

\subsection{Bridge Specifications}

In this study, the model of Sadr elevated bridge, as the first elevated bridge in Iran, located in the north-east of Tehran was used. The total length of the bridge is $6.6 \mathrm{~km}$, which about $5 \mathrm{~km}$ is from the main bridge and the rest is the access ramp. The spans of the bridge are $44 \mathrm{~m}$, and the expansion joints are located in the deck at intervals of four spans (at a distance of $176 \mathrm{~m}$ ), which separate the deck from each other. Figure 1(a) illustrates two photographs of this bridge. The deck of the bridge is prefabricated, which is located on concrete foundations. The deck consists of two concrete boxes next to each other with a width of $10.85 \mathrm{~m}$ and a height of $2.5 \mathrm{~m}$, which are placed one meter to the edges. The pier cap section has a width of $4.90 \mathrm{~m}$ and the average height of about $3 \mathrm{~m}$. Each box of the bridge deck is located on the four isolators. Since the friction bearings have the more appropriate performance for the horizontally curved bridges (Seo and Linzell (2013)), the friction bearings were used as a seismic isolation system in the present study. Seismic lateral loads applied to the deck were transferred to the bridge piers through the isolators. The diaphragm on the box girder deck is located at the above of pier. The substructure system of this bridge includes single concrete piers with a nearly circular section of $3 \mathrm{~m}$ in diameter and a height of approximately $7 \mathrm{~m}$.

Figure 1(b) displays the cross-section of the deck and the piers and the position of the deck on the pier cap. The foundation of the piers includes pile cap with $10.9 \mathrm{~m} * 6.4 \mathrm{~m}$ dimensions and 2-meter thickness and consists of eight 20 meter piles in length. The bridge is located in a very high seismic zone with an acceleration coefficient of $0.35 \mathrm{~g}$ defined by Iranian Code of Practice for Seismic Resistant Design of Building (Standard No.2800 Code, 2014). Additionally, the seismic design was performed for bridge. Self-consolidating concrete (SCC) was used for constructing the bridge components. The compressive strengths of the concrete used on the deck, the piers, and the pier cap are 450,400 and $350 \mathrm{~kg} / \mathrm{cm}^{2}$, respectively. The modulus of elasticity of the concrete pier is $3.02 \mathrm{e} 5 \mathrm{~kg} / \mathrm{cm}^{2}$. The rebar grade is S400 with yielding strength of $4000 \mathrm{~kg} / \mathrm{cm}^{2}$ and the ultimate strength of $6000 \mathrm{~kg} / \mathrm{cm}^{2}$. The steel modulus of elasticity is $2.1 \mathrm{e} 6$ $\mathrm{kg} / \mathrm{cm}^{2}$. 


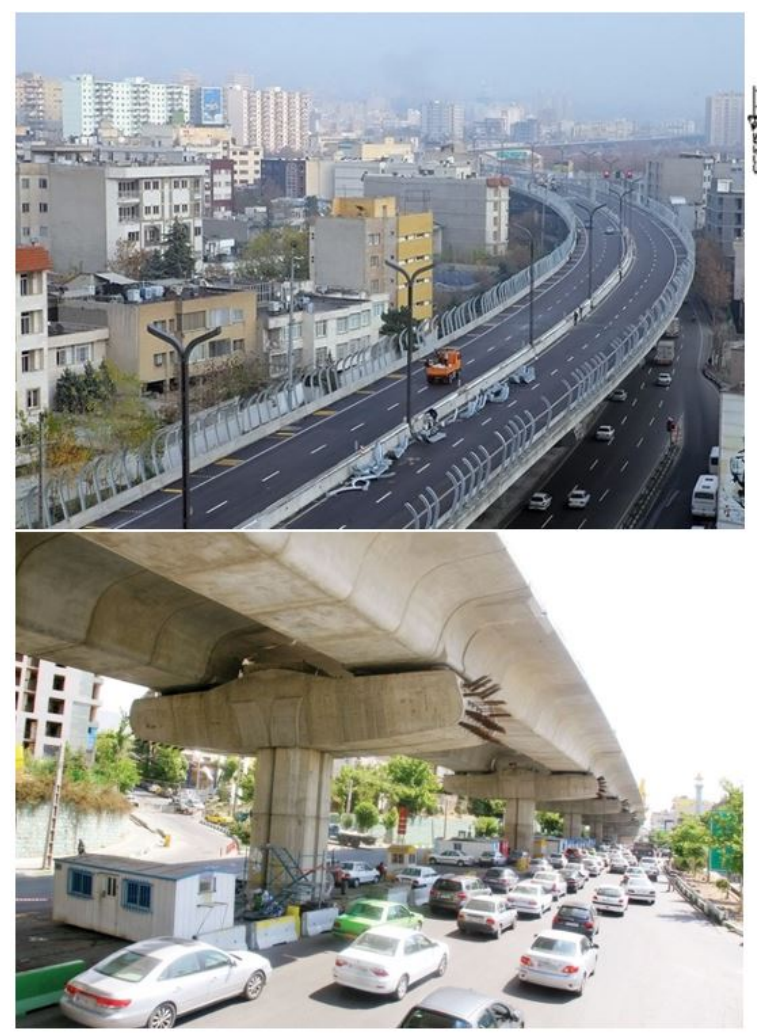

(a) Photographs of Sadr Bridge

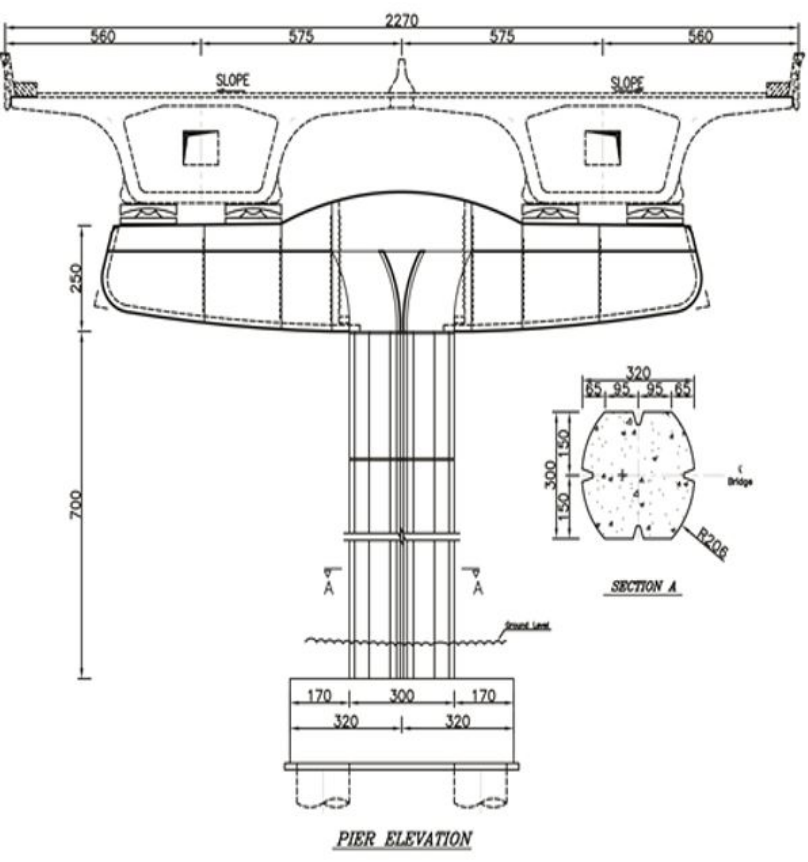

(b) the cross-section of the bridge deck

Figure 1: Sadr Bridge specification

In order to evaluate the effect of changes in the radius of the arc in plan, the deck of the bridge was modeled in the central arc angle of $0^{\circ}$ (straight bridge), $45^{\circ}, 90^{\circ}, 135^{\circ}, 180^{\circ}$ equivalent to arc radius $\infty, 224 \mathrm{~m}, 112 \mathrm{~m}, 74.7 \mathrm{~m}, 56 \mathrm{~m}$, respectively. The central arc angle is the central angle of the circle sector of the curved deck. All of the studied bridges have four spans in length of $44 \mathrm{~m}$ and a constant length of the arc of $176 \mathrm{~m}$. The plans of the curved bridges are shown in Figure 2. All of these bridges are considered in two isolated and non-isolated states. 


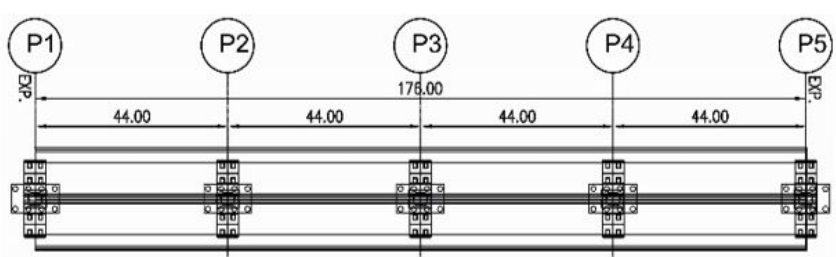

(a) Straight bridge (arc angle: $0^{\circ}(\mathrm{R}=\infty)$ )

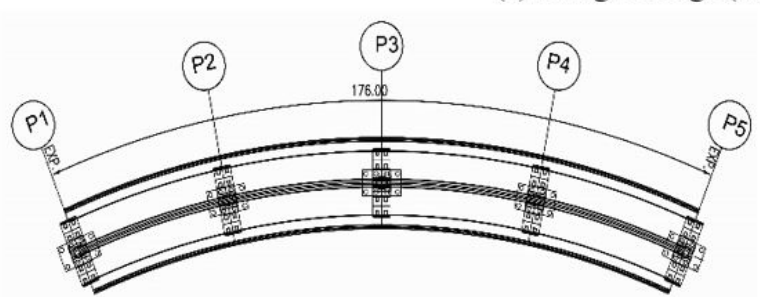

(b) Central Arc angle: $45^{\circ}(\mathrm{R}=224 \mathrm{~m})$

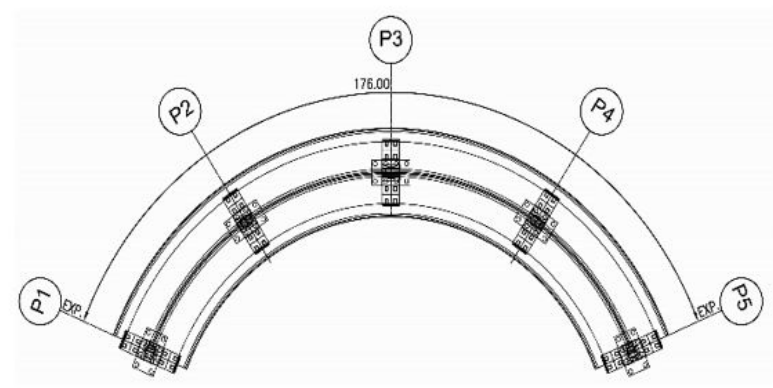

(d) Central arc angle: $135^{\circ}(\mathrm{R}=74.4 \mathrm{~m})$

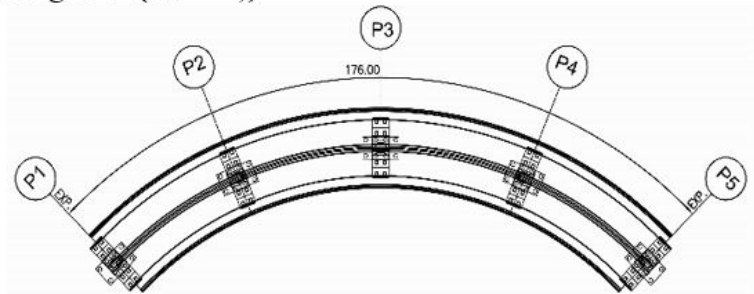

(c) Central arc angle: $90^{\circ}(\mathrm{R}=112 \mathrm{~m})$

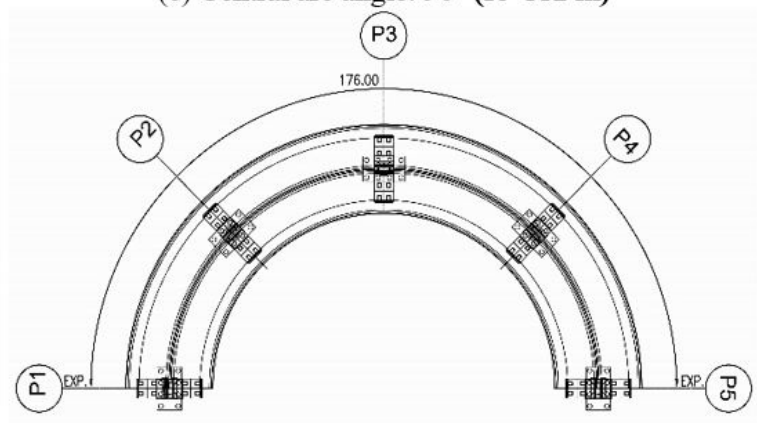

(e) Central arc angle: $180^{\circ}(\mathrm{R}=56 \mathrm{~m})$

Figure 2: The plan of the deck in the studied bridges for different arc radii

\subsection{Three-dimensional modeling of the bridge structure}

Three-dimensional bridge modeling was done by OpenSees (Mazzoni et al. (2008)) and confirmed by CSI Bridge (2015) software. As the bridge deck behaved linearly on the isolated bridge (Padgett and DesRoches (2008)), it was modeled by elastic elements. However, nonlinear behavior of deck materials is considered in the modeling of the nonisolated bridge. Distributed plasticity with fiber sections throughout the piece length is used for nonlinear modeling of the members. The Kent-Scott-Park model was used which is defined in OpenSees (2016) with Concrete02 materials for modeling the uniaxial behavior of confined concrete materials in the concrete core and unconfined concrete in cover. This model has linear behavior in the descending region in the stress-strain diagram under pressure and has linear behavior in the loading and unloading region in tension. The Giuffre-Menegotto-Pinto steel material model is used with isotropic hardening, which is defined in OpenSees with steel02 materials for modeling reinforcement in concrete sections of the piers and deck of the bridge. In addition, the singleFPBearing element is used to model the nonlinear behavior of frictional isolators in 3D models. The bridge deck element has been modeled on the central axis of the deck and is connected to the top of the isolators with a rigid element. Isolators have three-dimensional correlated frictional properties including post-yielding stiffness due to concavity of the sliding plate for shear deformation. The rotation of sliding the concave plate affects the shear behavior of frictional isolators (Mazzoni et al. (2008)).

Figure 3 illustrates a schematic configuration of 3D modeling for bridge components and FPB in OpenSees. In the present study, the effect of SSI was ignored. Therefore, the support of all piers was modeled in a fixed state. The concentrated mass of the deck was applied at 2-meter distances, along the deck. 

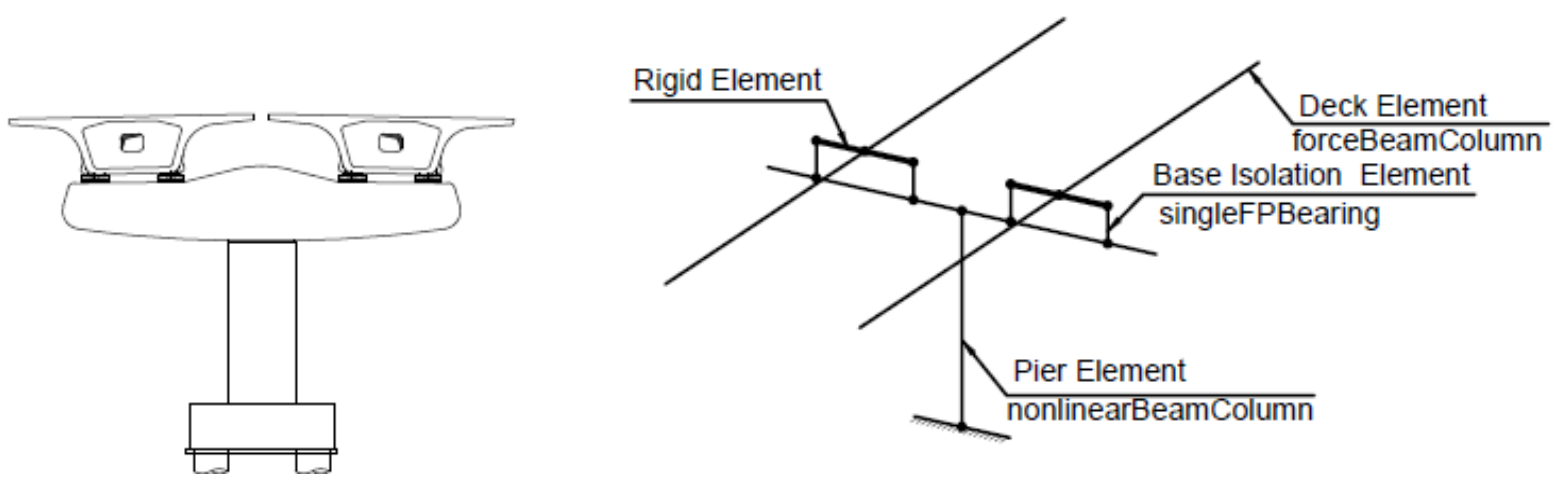

Figure 3: A schematic configuration of 3D bridge modeling in OpenSees

FPB comprising a spherical sliding surface of stainless steel, a slider coated with a PTFE-type composite material and a housing plate. The lateral capacity of FPB is considered as the sum of the restoring force due to the upward movement of the structure mass on the sliding surface $F_{s}$ and the force due to the friction of the sliding surfaces $F_{f}$, as follows:

$F=F_{S}+F_{f}=\frac{W}{R} u+\mu W \operatorname{sgn}(\dot{u})$

Where $\mathrm{W}$ represents the force of weight applied to the isolator, $u$ and $\dot{u}$ is considered as the horizontal displacement and velocity of the isolator, respectively. $\mathrm{R}$ indicates the curve radius of the concave plate of the isolator, and $\mu$ represents the slip friction coefficient. In FPB modeling, a linear spring and a friction damper are used in parallel for consideration of restoring force and friction force, respectively. The effective stiffness is equal to the secant stiffness of the isolation system in the excitation domain. Effective damping is equal to the equivalent viscous damping value defined by the hysteresis cycle in the excitation amplitude (FEMA 451).

In this study, friction seismic isolators were designed according to ASCE 7-16. Table 1 represents the specifications of the friction isolators used in the isolator modeling where $\zeta_{\text {eff }}$ indicates the effective damping, $K_{\text {eff }}$ represents the effective stiffness and $K_{\text {post }-Y}$ is post-yielding stiffness.

Table 1: Specifications of FPB used in modeling

\begin{tabular}{cc}
\hline Dynamic mechanical properties & Values \\
\hline$\zeta_{\text {eff }}$ & $12.7 \%$ \\
$\mathrm{~K}_{\text {eff }}(\mathrm{t} / \mathrm{m})$ & 149.5 \\
$\mathrm{~K}_{\text {post- } \mathrm{Y}}(\mathrm{t} / \mathrm{m})$ & 119.6 \\
$\mu$ & 0.0527 \\
$\mathrm{~W}(\mathrm{ton})$ & 244 \\
$\mathrm{R}(\mathrm{m})$ & 2.04 \\
\hline
\end{tabular}

\section{SPECIFICATIONS OF SELECTED GROUND MOTIONS}

Long-period velocity pulses occur at the beginning of the earthquake record in the perpendicular component of the fault when the fault is ruptured toward the desired site and the fault rupture distribution velocity is close to the shear wave velocity. This phenomenon is called "Forward Directivity" and ground motions located near the fault have such a feature (Somerville (1998)). In order to compare the behavior of horizontally curved bridges under the influence of near-field and far-field earthquakes, the component perpendicular to the fault of four ground motions with the effect of forward directivity pulse was selected among 91 ground motions containing forward directivity effect introduced by Baker (2007). Table 2 shows the characteristics of the selected near-fault ground motions. As shown, $T_{p}$ is considered as the pulse period in the near-field ground motion. The far-fault ground motions were selected from the same stations where the near-field ground motions were recorded. In fact, the specifications of the site, the type of soil 
are completely identical for the two series of far-field and near-field ground motions and the comparison of the results is more realistic. Table 3 presents the characteristics of the far-field ground motions. Peak Ground Acceleration (PGA) of all ground motions (near-field and far-field) scaled to the design base acceleration is equal to $0.35 \mathrm{~g}$. There are velocity pulses in near-fault ground motions. For example, Figures $4(\mathrm{a})$ and $4(\mathrm{~b})$ display the velocity time series of the near-field (Northridge-01) and far-field (Whittier Narrows) ground motions both for the Sylmar station. As shown in Figure 4(a), the velocity pulse can be observed in the velocity time series of near-fault ground motion. Figure 5 shows the acceleration response spectra with a $5 \%$ damping of near-field and far-field selected ground motions.

Table 2: Selected near-field ground motions

\begin{tabular}{cccccc}
\hline Earthquake Name & Station & PGA(g) & $\mathbf{M}_{\mathbf{w}}$ & $\mathbf{R}_{\mathbf{j b}}(\mathbf{k m})$ & $\mathbf{T}_{\mathbf{P}}(\mathbf{s e c})$ \\
\hline Loma Prieta -1 & Gilroy Array \#2 & 0.406 & 6.93 & 10.38 & 1.7 \\
Morgan Hill-1 & Coyote Lake Dam & 0.814 & 6.19 & 0.18 & 1.0 \\
Northridge-01 & Sylmar & 0.732 & 6.69 & 1.74 & 3.1 \\
Superstition Hill-02 & Parachute Test Site & 0.418 & 6.54 & 0.95 & 2.3 \\
\hline
\end{tabular}

Table 3: Selected far-field ground motions

\begin{tabular}{cccccc}
\hline Earthquake Name & Station & $\mathbf{P G A}(\mathbf{g})$ & $\mathbf{M}_{\mathbf{w}}$ & $\mathbf{R}_{\mathbf{j b}}(\mathbf{k m})$ & $\mathbf{T}_{\mathbf{p}}(\mathbf{s e c})$ \\
\hline Morgan Hill -2 & Gilroy Array \#2 & 0.162 & 6.19 & 13.68 & - \\
Loma Prieta-2 & Coyote Lake Dam & 0.151 & 6.93 & 19.97 & - \\
Whittier Narrows & Sylmar & 0.057 & 5.99 & 38.55 & - \\
Imperial Valley & Parachute Test Site & 0.112 & 6.53 & 12.69 & - \\
\hline
\end{tabular}

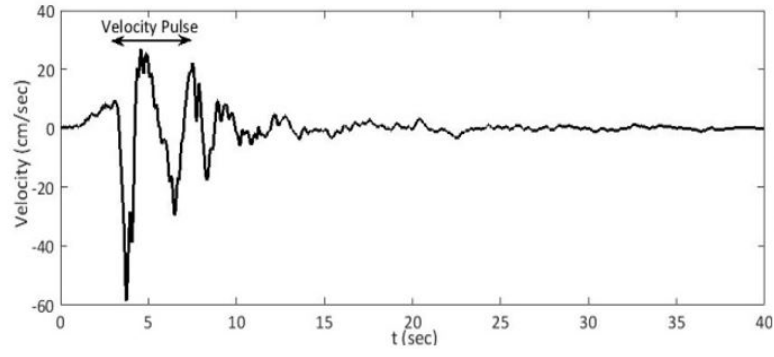

(a) the velocity time series of near-field (Northridge-01)

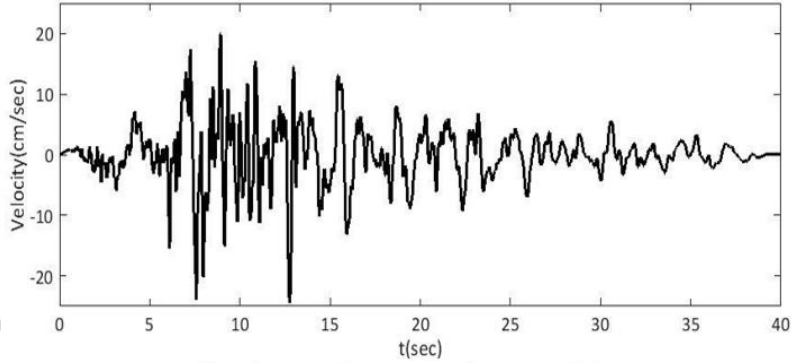

(b) the velocity time series of far-field (Whittier Narrows)

Figure 4: The velocity time series of far-field and near-field earthquake at Sylmar Station

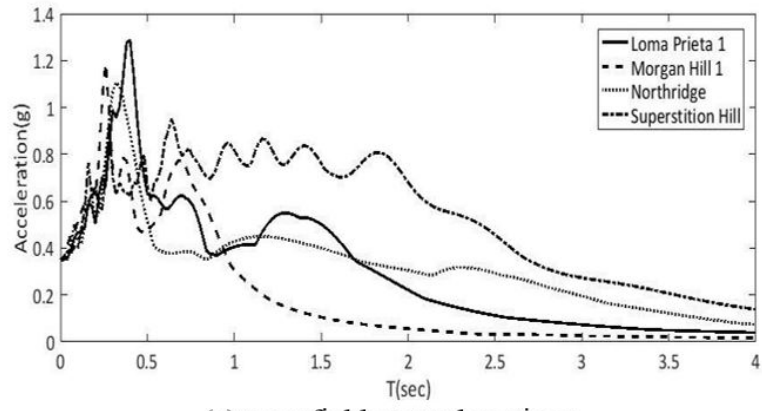

(a) near-field ground motions

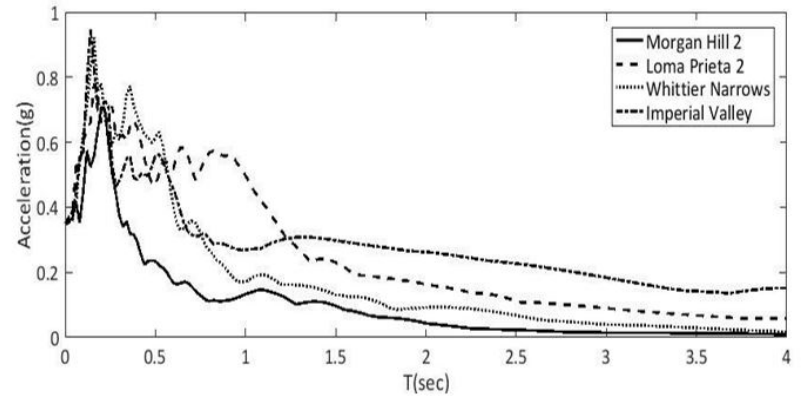

(b) far-field ground motions

Figure 5: Acceleration response spectra with 5\% damping

\section{RESULTS OF THE MODAL ANALYSIS}

Modal analysis is regarded as an appropriate method for evaluating the dynamic response of structures. Geometric characteristics of the structure have a significant influence on the structural vibration. Therefore, the changes in the angle of the arch on the bridge deck plan affect their dynamic response, and its dynamic behavior becomes more complicated (Soberón and Soberón, (2017)). For this purpose, the modal analysis was performed for the bridge with the straight and curved deck. Figure 6 illustrates the main vibrational mode shapes of the straight bridge and horizontally curved bridges with center angles of $90^{\circ}$ and $180^{\circ}$. As shown in Figure $6(\mathrm{a})$, the mode shape of the 
dominant mode with the largest mass participation contains displacement along the longitudinal axis of the bridge. While in the non-isolated curved bridge the dominant mode involves the combination of longitudinal and torsional displacements. Figures $6(\mathrm{~b})$ and $6(\mathrm{c})$ displays the dominant mode shape of the curved bridge with the central arc angle of $90^{\circ}$ and $180^{\circ}$, respectively. In Tables 4 and 5, the main mode period and the percentage of mass participation of the dominant mode in the isolated and non-isolated bridges are given for different arc angles, respectively.

In the non-isolated bridges, an increase in the central arc angle leads to a reduction in the main period of the bridge. By increasing the central arc angle, the mass participation rate of the dominant mode decreases along the longitudinal and transverse directions. Thus, the mass participation of the bridge with a central arc angle $180^{\circ}$ to the straight bridge direction decreases about $67 \%$ and $31 \%$ in the longitudinal and transverse direction, respectively. In the straight bridge, it has $95 \%$ mass participation in the dominant mode alone, while 14 and 23 modes are required in the curved bridge with $90^{\circ}$ and $180^{\circ}$, respectively, to achieve $90 \%$ mass participation. In other words, an increase in the curvature of the non-isolated bridge leads to an increase in the contribution of the mass participation of the higher modes of the structure. The high modes of the curved bridge are often torsional, leading to the interaction between modes and the complexity of the behavior in the structure. It should be noted that period and mass participation variations are insignificant up to the angle of $90^{\circ}$, compared to the straight bridge. Therefore, the use of dynamic analysis is necessary for curved bridges with a high arc central angle (greater than $90^{\circ}$ ).

Regarding the isolated bridge, the period of the dominant mode increased due to increment central arc angle. The mass participation value of the dominant modes in the longitudinal direction decreased with increasing curvature. Consequently, the ratio of mass participation of the curved bridge with the central angle of $180^{\circ}$ to the straight bridge reduced by $20 \%$. However, the mass participation in the transverse direction at all angles is almost constant. Therefore, unlike the non-isolated bridges, no significant difference is found between the mass participation of horizontally curved bridges and straight bridges in isolated curved bridges. In all the isolated bridges, the main mode is the first mode and involves moving along the longitudinal and transverse directions of the bridge. Therefore, the seismic isolation improves the complexity of the dynamic response in the non-isolated curved bridges.

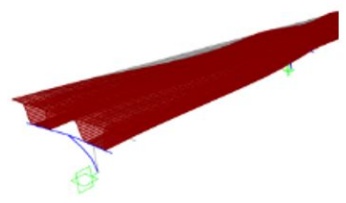

(a) Straight bridge

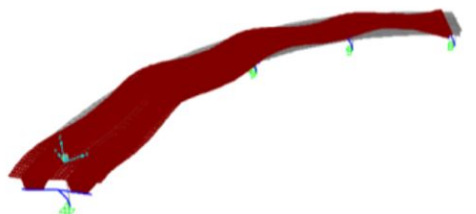

(b) Curved bridge with the central arc angle of $90^{\circ}$

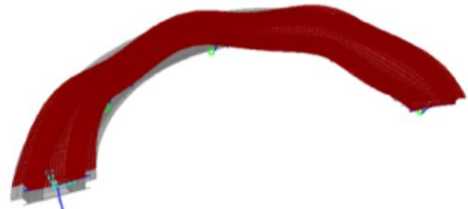

(c) Curved bridge with the central arc angle of $180^{\circ}$

Figure 6: Vibrational modes of the non-isolated bridge (CsiBridge2015 Software Model)

Table 4: The period of dominant modes in the bridge for different central arc angles

\begin{tabular}{cccccc}
\hline & $\alpha=0^{\circ}$ & $\alpha=45^{\circ}$ & $\alpha=90^{\circ}$ & $\alpha=135^{\circ}$ & $\alpha=180^{\circ}$ \\
\hline Non-isolated & 0.606 & 0.582 & 0.561 & 0.527 & 0.51 \\
Isolated & 2.78 & 2.78 & 2.8 & 2.85 & 2.92 \\
\hline
\end{tabular}

Table 5: the percentage of mass participation in the dominant mode for different central arc angles

\begin{tabular}{ccccccc}
\hline & Direction & $\alpha=0^{\circ}$ & $\alpha=45^{\circ}$ & $\alpha=90^{\circ}$ & $\alpha=135^{\circ}$ & $\alpha=180^{\circ}$ \\
\hline Non-isolated & $\mathrm{X}$ & 95 & 90 & 85.6 & 54.4 & 31 \\
& $\mathrm{Y}$ & 33.5 & 33 & 32.7 & 30.5 & 23.1 \\
Isolated & $\mathrm{X}$ & 64.8 & 63.7 & 60.9 & 56.8 & 51.3 \\
& $\mathrm{Y}$ & 64.8 & 64.7 & 64.5 & 64.7 & 64.7 \\
\hline
\end{tabular}

\section{RESULTS OF NONLINEAR TIME HISTORY ANALYSIS}

Compared to straight bridges, horizontally curved bridges have different responses due to the geometry of their deck under the effect of ground motions. To this end, the seismic behavior of studied curved bridges was investigated in the non-isolated (fixed connection between pier and deck) and isolated states under the influence of selected near and far-field earthquakes. Then, the seismic assessment of deck and piers was performed in the radial and tangential directions. The component perpendicular to the fault with forward directivity effect in near-fault ground motion and 
the component having larger PGA in the far-field earthquake were applied to the longitudinal axis of the bridge. In the next procedure, nonlinear time history analysis was performed for each selected ground motions. Also, Average of Maximum Shear force (AMS) and Average of Maximum Drift (AMD) were determined at bridge piers and deck for each bridge at different central arc angles.

\subsection{Evaluation of the seismic response of the bridge piers}

The results of the time history analysis indicated that an increase in the curvature of the curved bridges results in changing the demand for force and displacement, depending on where each of the piers is located at the bridge. The position of each of the bridge piers (P1 to P5) is shown in Figure 2. The position of the piers P4 and P5 is similar to that of piers $\mathrm{P} 2$ and $\mathrm{P} 1$, respectively.

Figures 7 and 8 display the values of AMS for each of the piers P1, P2 and P3 derived from the nonlinear time history analysis for the non-isolated and isolated bridges with different central arc angles, respectively. As illustrated in Figure 7, the tangential shear force in the piers P1 and P2 has the maximum value (which approximately equal together) for near-field and far-field earthquakes in the straight non-isolated bridge, which are $1.5 \mathrm{~W}$ and $1.15 \mathrm{~W}$, respectively. $W$ represents the weight force applied to the pier P2 (middle pier of the bridge) and equal to 1700 tons. The tangential direction in the straight bridge is the longitudinal axis of the bridge. In the bridge with arched deck, an increase in the curvature leads to a decrease in the tangential shear force in the piers P1 and P2 relative to the straight bridge, so that the AMS on the pier P1 in the half-circle deck $\left(\alpha=180^{\circ}\right)$ for the near-field and far-field ground motion decrease $63 \%$ and $58 \%$ than the straight bridge, respectively, while in the pier P2 it can decrease $34 \%$ and $30 \%$ than the straight bridge, respectively. However, the tangential shear force approximately is constant and independent of the curvature variation in the pier P3. Regarding the pier P3, the tangential shear force for the straight bridge in near-field and far-field earthquakes is $1.15 \mathrm{~W}$ and $0.88 \mathrm{~W}$, respectively. The radial shear force of all the piers in the straight bridge is approximately equal to zero, but the radial shear force increases by increasing the central arc angle in the curved bridges for all piers. Thus, its maximum value is related to angle $180^{\circ}$ (bridge with half-circle arc deck). Regarding the pier $\mathrm{P} 1$, the maximum radial of AMS in the near-field and far-field ground motions are $0.5 \mathrm{~W}$ and $0.43 \mathrm{~W}$, in the pier $\mathrm{P} 2$ are $0.6 \mathrm{~W}$ and $0.47 \mathrm{~W}$ and in the pier $\mathrm{P} 3$ are $0.24 \mathrm{~W}$ and $0.19 \mathrm{~W}$, respectively. As observed, the radial AMS for the piers $\mathrm{P} 2$ and $\mathrm{P} 3$ have the maximum and minimum value, respectively.

The seismic isolation reduces the shear force in the bridge piers significantly, leading to a reduction in the damage to the substructure and an improvement in the seismic performance of the bridge. Based on the comparison of Figures 7 and 8, the AMS in the piers P1 and P2 of the isolated bridge is about one-third of the piers of the non-isolated bridge and the tangential and radial AMS changes are approximately the same as non-isolated bridges. In the isolated bridge, the radial shear force created in the pier P3 is very small. As shown in Figures 7 and 8, AMS due to near-fault ground motions for the isolated structure is greater than the shear force caused by the far-field ground motions, as well as the non-isolated structure. Furthermore, the seismic isolation decreases the difference in the value of AMS in the bridge piers due to the changes in the central arc angle.
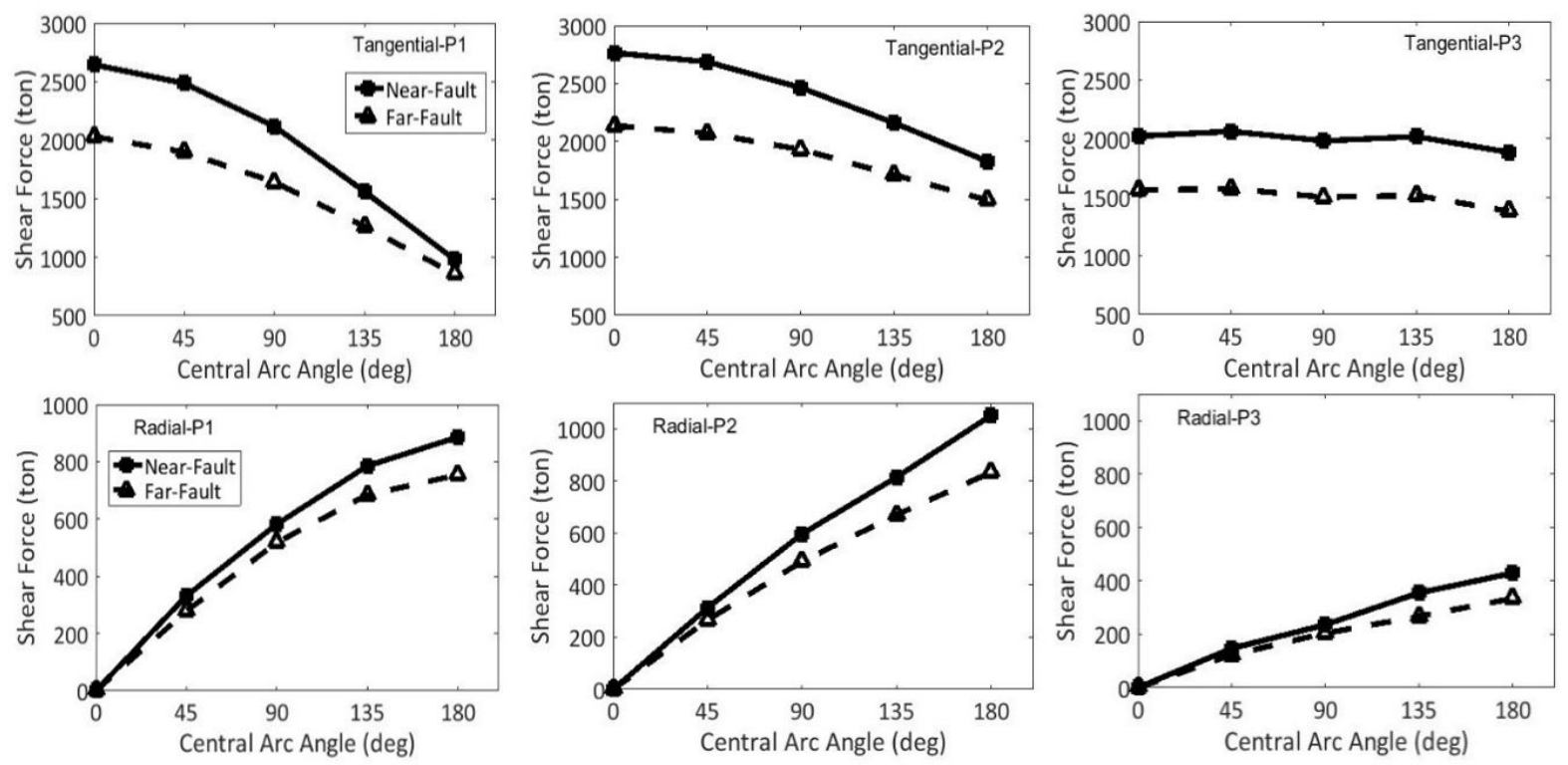

Figure 7: AMS of piers for the near-field and far-field ground motion in the non-isolated bridge 

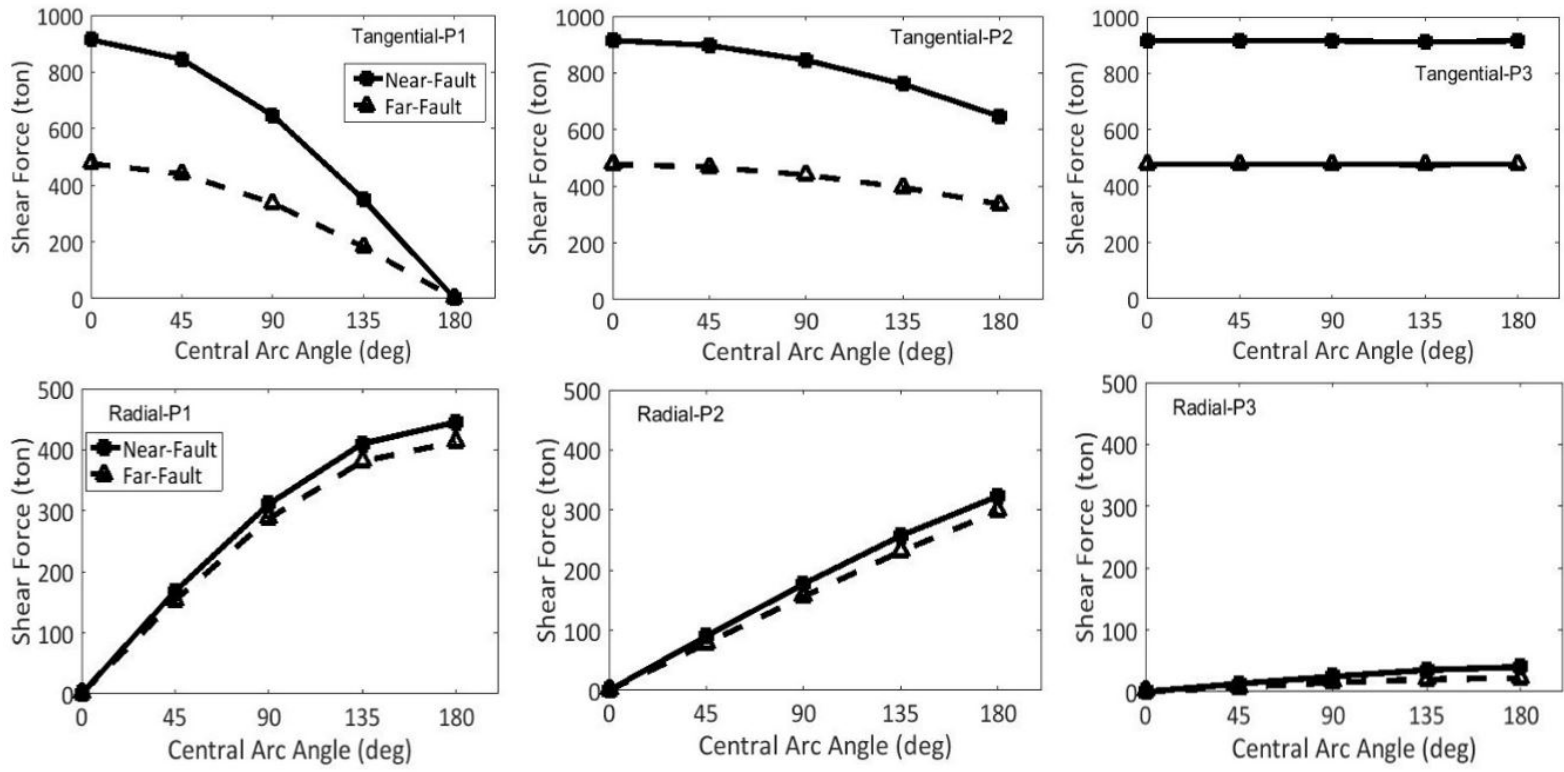

Figure 8: AMS of piers for the near-field and far-field ground motion in the isolated bridge by FPB

The variations of AMD for piers P1, P2 and P3 of the non-isolated bridge in the radial and tangential directions are shown in Figure 9. The displacement of the piers P1 and P2 decreases with increasing curvature of deck in tangential direction. The displacement of all piers approximately equal to zero in straight bridge and the displacement of the piers $\mathrm{P} 1$ and $\mathrm{P} 2$ in the radial direction at the central arc angle of about $90^{\circ}$ has its maximum value in curved bridge. In addition, the tangential displacement of the pier P3 is approximately constant and its radial displacement change is negligible. Further, the displacement of the piers in the isolated structures is insignificant (so its figures are not shown). Finally, as shown in Figures 7-9, the variations in the tangential AMS and AMD of all piers up to the $\alpha=45^{\circ}$ central arc angle are not significantly different from the straight bridge. The AMD due to near-fault ground motion is greater than far-fault ground motion. The maximum ratio of AMD due to near-fault grounds motion to the far-fault ground motions related to straight bridge and equal to 1.5 and the difference between them decreases with increasing central arc angle.
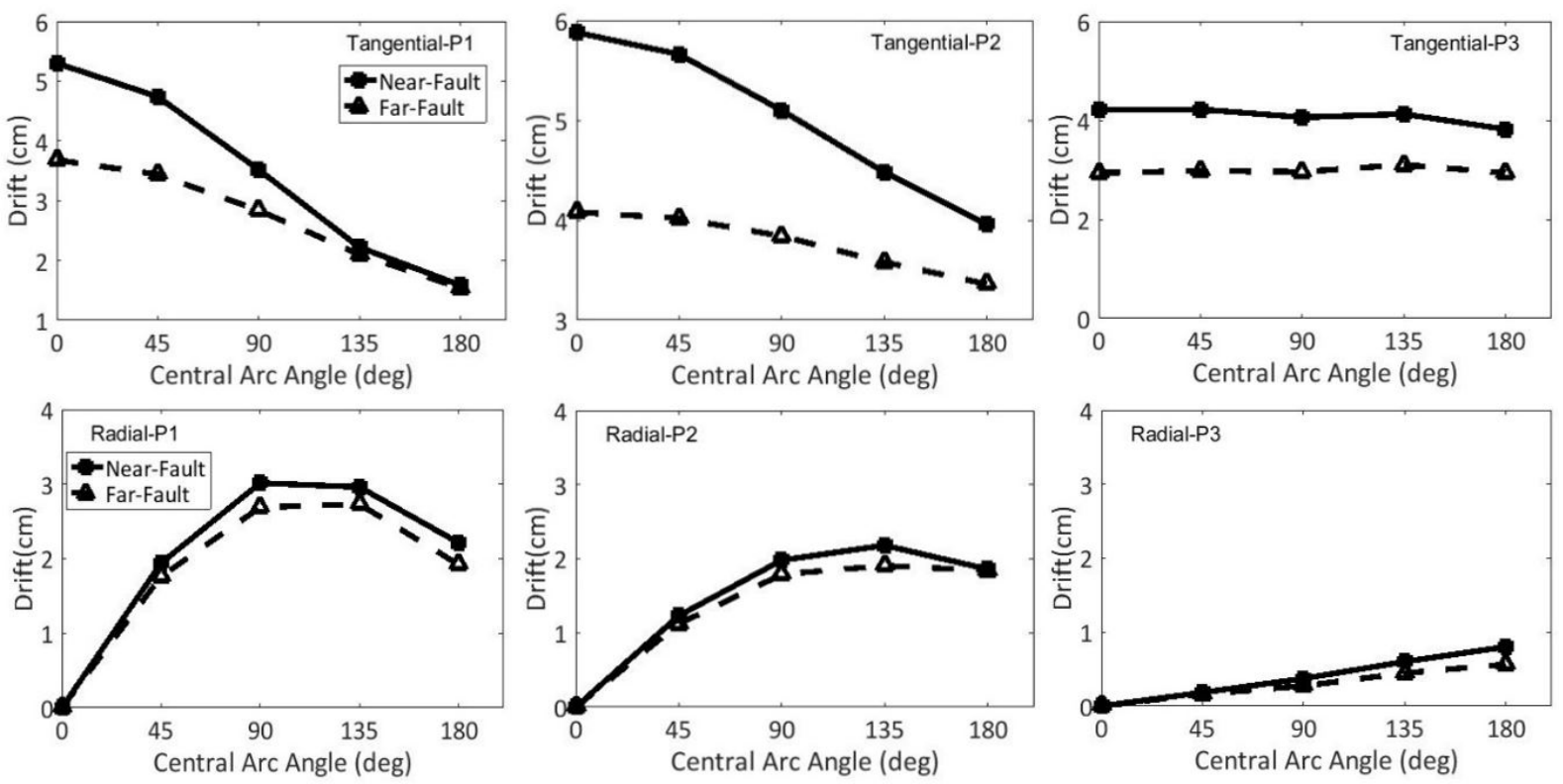

Figure 9: AMD for the near-field and far-field ground motion in the non-isolated bridge

The evaluation of the seismic performance of the structural members is possible by evaluating the displacementforce behavior. For this purpose, the nonlinear force-displacement diagram of the piers was prepared for a near-fault ground motion of Tabas with PGA=0.861g and $\mathrm{M}_{\mathrm{w}}=7.35$ from the Tabas Station. As an example, the lateral hysteresis 
loop of the pier P2 for a straight bridge and horizontally curved bridges with the central arc angle equal to $90^{\circ}$ and $180^{\circ}$ for the non-isolated bridge in two tangential and radial directions are shown in Figure 10. As shown in the first row of this figure, the pier P2 has plastic deformations in the tangential direction. An increase in the central arc angle leads to a slight reduction in the displacement range. The second row in Figure 10 displays the lateral force-displacement behavior in the radial direction of the bridge. As shown, the lateral force-displacement behavior of the straight bridge is insignificant and is relatively linear for a bridge with the arc angle of $90^{\circ}$. By increasing the central arc angle more than $90^{\circ}$, the pier P2 has plastic deformations, which suffer more damage.

The results indicated that no plastic deformation was made in all of the isolated bridge piers and the piers remained in the elastic range and damage does not occur. The lateral hysteresis loop of the FPB located on the pier P2 in tangential and radial directions are shown in Figure 11. As shown, by increasing the central arc angle, the displacement of the deck and the lateral forces on the isolator increase significantly in the radial direction.
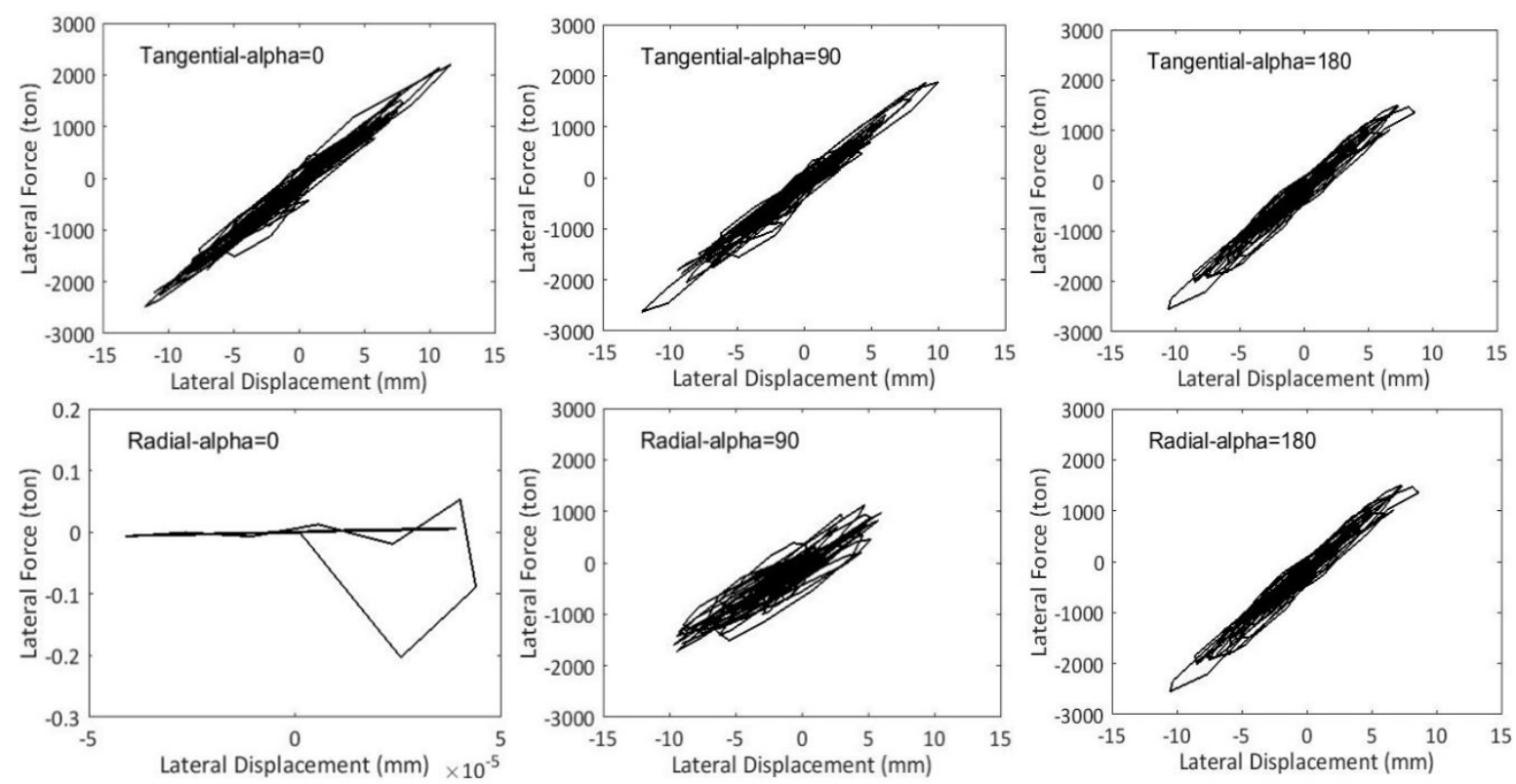

Figure 10: The lateral force-displacement loop of pier P2 of the non-isolated bridge for Tabas near-field earthquake
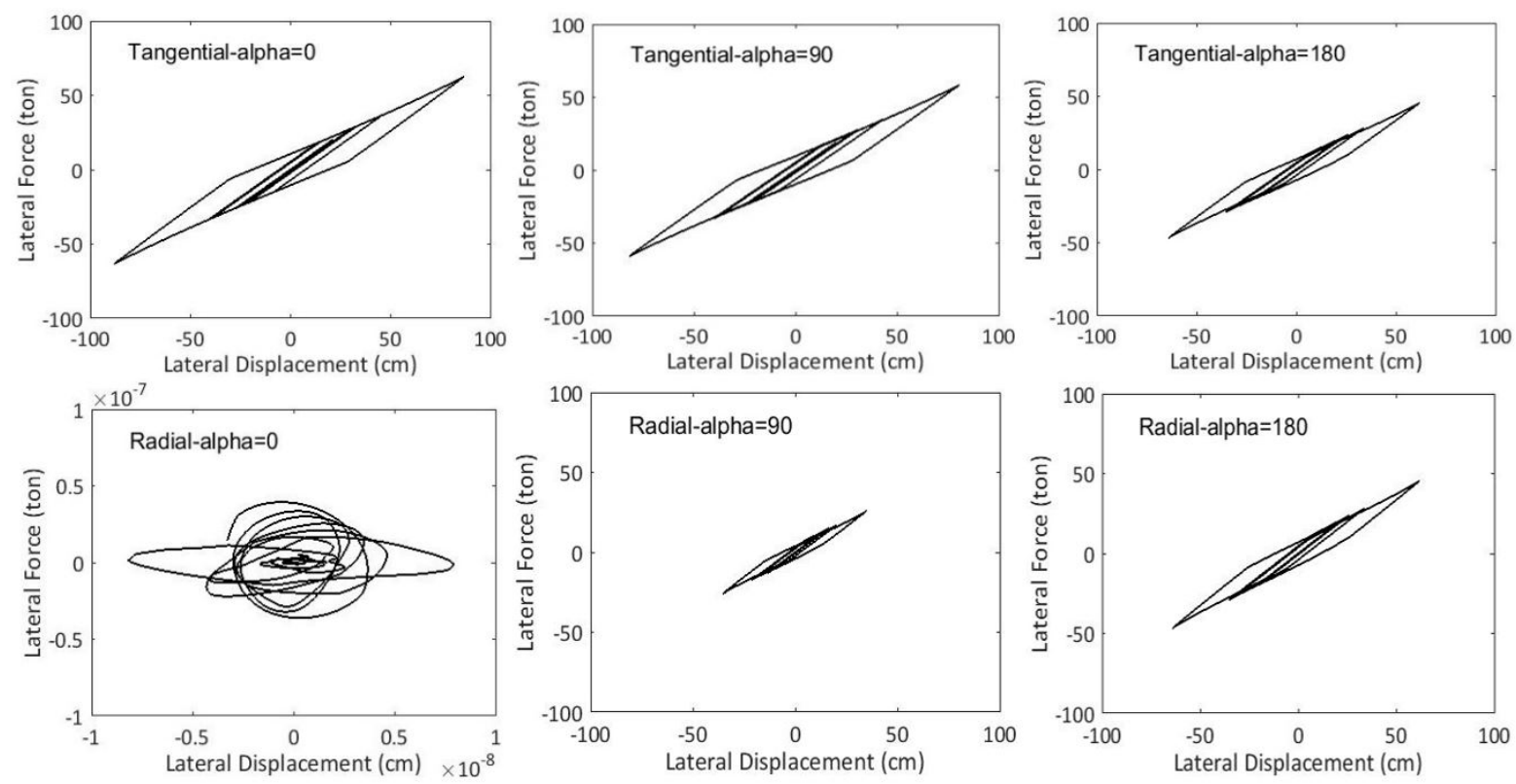

Figure 11: The lateral force-displacement loop of FPB located at pier P2 for Tabas near-field earthquake 


\subsection{Assessment of the Deck Seismic Response}

In this section of the study, the seismic response of curved decks is studied. The displacement of the deck of the isolated bridge is amplified due to the velocity pulses that are exist in the ground motion involving the forward directivity effects. For example, Figure 12 displays the displacement of the deck in the straight bridge equipped by FPB for the near and far-field earthquakes in the longitudinal direction for the Sylmar and Gilroy Array \#2 stations. As observed, the displacement of near-fault earthquakes in bridges which isolated by FPB is significantly more than farfault earthquakes, so that the maximum deck displacement ratios of the near-fault to the far-fault ground motions at Sylmar and Gilroy Array \#2 stations are 2.74 and 4.92, respectively. It can refer to the presence of a velocity pulse in near-fault ground motions with the period around the dominant period of the isolated bridge which amplifies the deck displacements (resonance phenomenon) (Jangid (2005)).

The average values of the maximum bending moment around the horizontal (radial direction and major bending moment) and vertical axis (minor bending moment) in the deck, the average values of the maximum shear force along the radial direction (minor shear force) and along vertical direction of the deck (major shear force), as well as the average values of the maximum deck torsion for different central arc angles are determined by using nonlinear time history analysis for the isolated and non-isolated bridge (Figure 13). As shown in Figure 13(a), for the non-isolated bridges, the values of all responses increase by increasing deck curvature, and the maximum response value in all cases is related to the bridge with the maximum central arc angle $\left(\alpha=180^{\circ}\right)$. Also, the ratios of the major bending moment of the deck and the major shear force of the deck on the bridge with a central angle of $180^{\circ}$ to the straight bridge are 1.46 and 1.33, respectively. As shown, the absolute value of minor shear force, torsion and minor bending moment for the straight bridge are approximately equal to zero. These values increase significantly through increasing central arc angle. Thus, the maximum of these values for the bridge with the maximum curvature ( $\left.\alpha=180^{\circ}\right)$ indicates an increase of 465 tons, 3925 t.m, 5723 t.m than to the straight bridge, respectively. The force increasing rate is high up to $90^{\circ}$, while this difference decreases above this angle. For example, the ratio of the maximum minor bending moment at central arc angles $180^{\circ}$ to $135^{\circ}$ is 1.16 , while the ratio of the maximum minor bending moment at central arc angles $90^{\circ}$ to $45^{\circ}$ is 1.58. As shown in Figure 13(b), for the isolated bridge, the average of the maximum of the minor shear force and the minor bending moment are significantly lesser than the non-isolated bridge, and the torsion is about half. The value of the major bending moment and the major shear force are not significantly reduced, because the significant contribution of them is due to gravity loading. It should be noted that the difference between the value of the bending moments, shear forces and torsion due to increases in deck curvature, considerably decreases by seismic isolation and is approximately equal to the value of the straight bridge. Therefore, the frictional seismic isolation eliminates the adverse effects of the high curvature of the deck such as increasing the force demand on the deck.

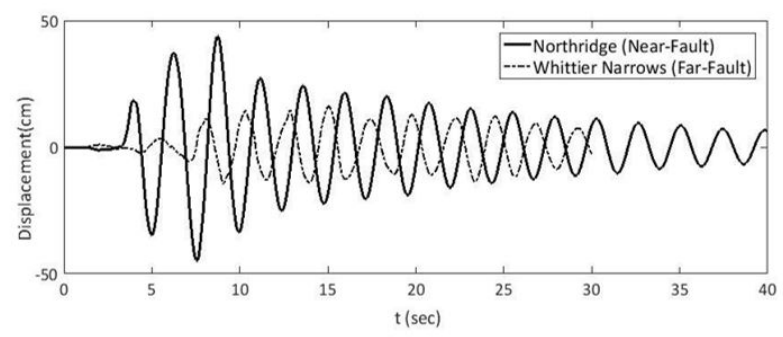

(a) Sylmar station

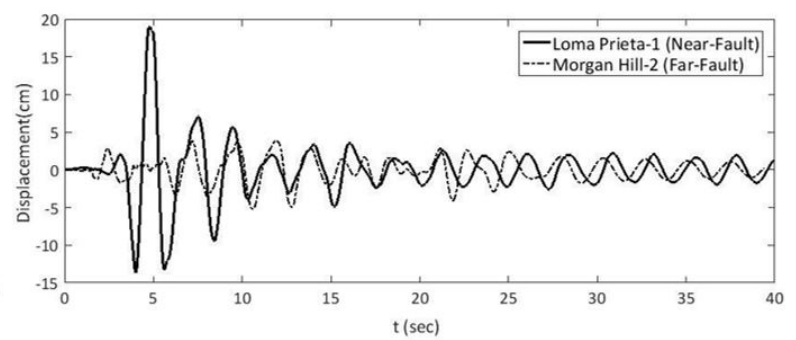

(b) Gilroy Array \#2 station

Figure 12: A comparison of the displacement in the deck of the straight bridge isolated by FPB under the near-field and far-field earthquake in the longitudinal direction 

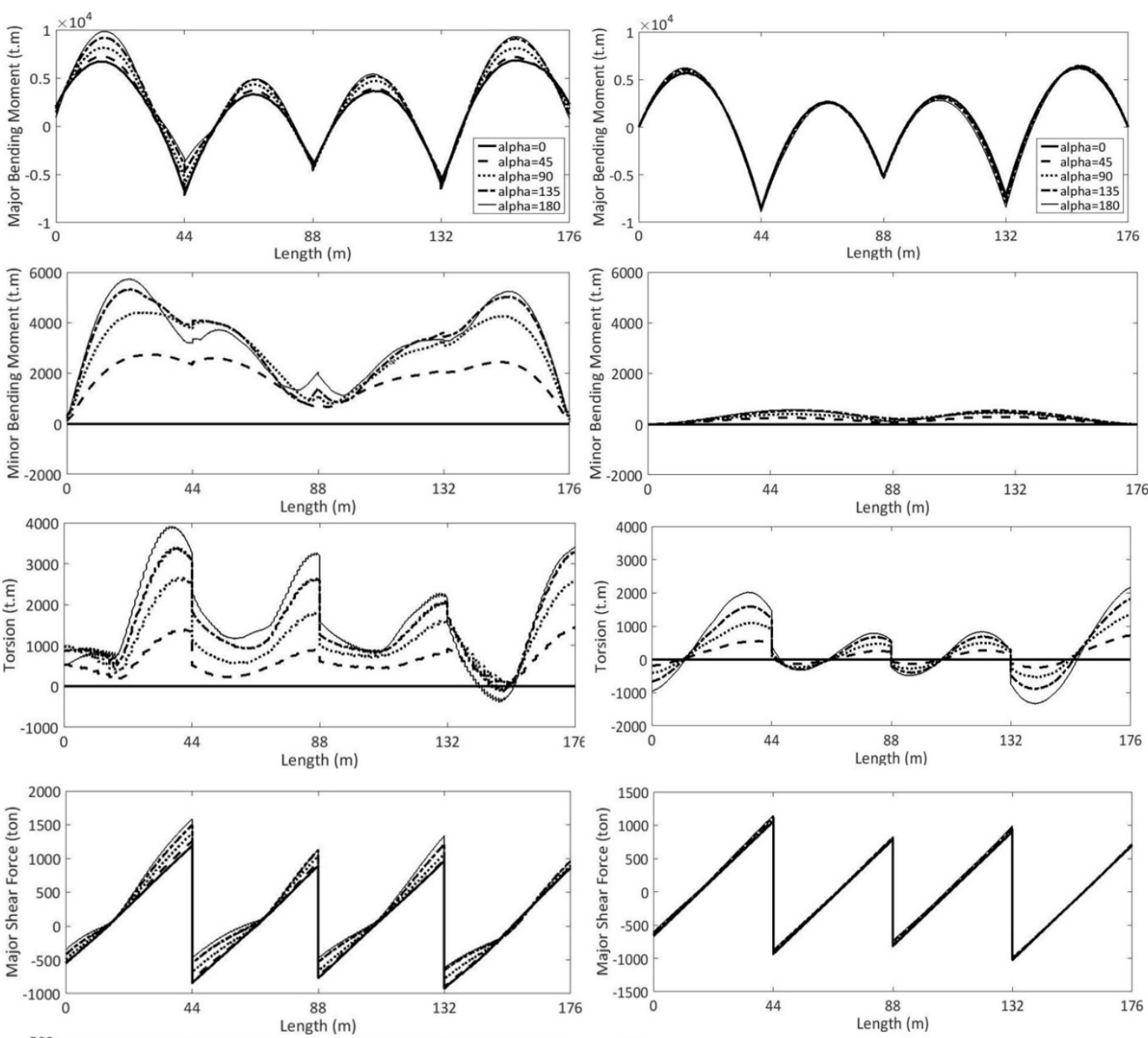

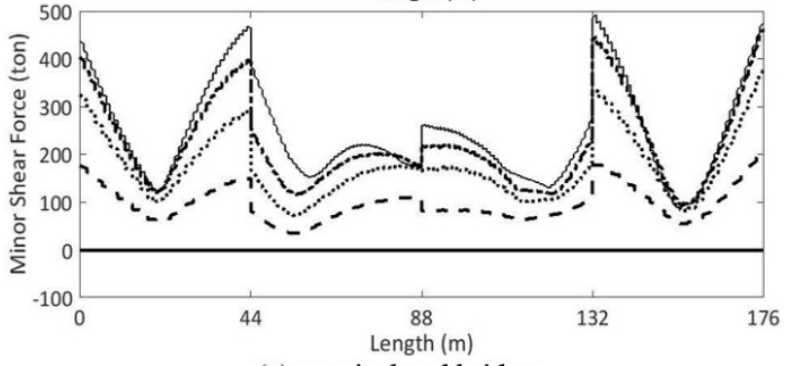

(a) non-isolated bridge

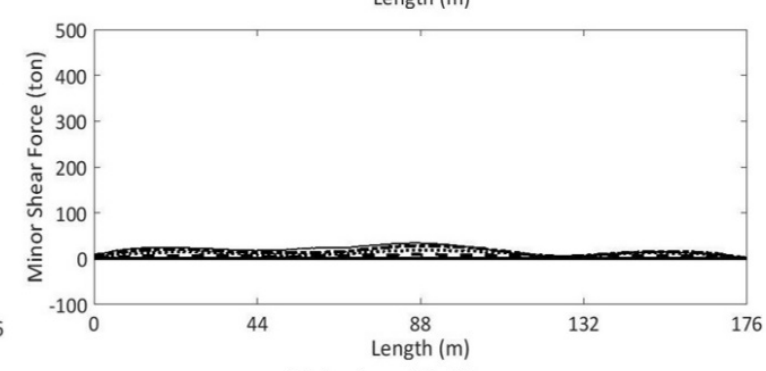

(b) isolated bridge

Figure 13: The average values of the maximum response in bridge deck of the near-field earthquakes for different arc radii of the deck

\section{CONCLUSIONS}

The present study focused on evaluating the seismic behavior of horizontally curved bridges. To this aim, Sadr Bridge, located in Tehran, was modeled with box deck in straight and horizontally curved forms with the central arc angle of $45^{\circ}, 90^{\circ}, 135^{\circ}$ and $180^{\circ}$. Then, the bridge was modeled in non-isolated and isolated states and the isolated bridge is equipped by FPB. In addition, near and far-fault ground motions were selected and scaled. In the next step, the modal analysis and the nonlinear time history analysis was performed. Finally, the demand values in the pier and deck and force-displacement diagram were compared in the studied bridges and the following results were obtained:

- $\quad$ Reducing arc radius or increasing central arc angle results in decreasing the shear force and displacement of the pier in the tangential direction and increasing the shear force and displacement of the pier in the radial direction. 
- Near-fault ground motions generate more force and displacement demand in the pier and deck of bridges. The displacement of the deck of the straight and horizontally curved bridge under the near-fault ground motions due to its pulse-like nature is considerably larger than the far-fault ground motions.

- Results of the nonlinear time history analysis indicated that an increase in curvature leads an increase in the plastic deformation of the piers in the radial direction in the force-displacement behavior of the piers. Those piers located between the beginning of the arch and the arch crown, pier P2 in this study, has larger forces and drifts and is more vulnerable consequently.

- Bridges with high central arc angle deck $\left(90^{\circ}\right.$ and higher angles) have dynamic irregularities. Thus, the participation of higher modes, which are mostly torsional, is high. In addition, seismic isolation improves the complex behavior of these bridges and reduces their irregularities.

- Increasing the curvature of deck results in increasing the force demand on the deck of the non-isolated bridge, especially the minor shear force, minor bending moment and torsion, leading to more vulnerability to the deck. Further, seismic isolation significantly reduces the adverse effects of the high curvature in the deck, and a slight difference is observed between forces and bending moments at different arc angles of the deck.

- The high curvature of the deck increases the vulnerability of the bridges more by increasing their force and drift. Seismic isolation by friction pendulum bearing plays a major role in reducing force and displacement demand and improving the seismic performance of horizontally curved bridges. Therefore, it is recommended to use seismic isolators for horizontally curved bridges with a central arc angle of $90^{\circ}$ and higher.

\section{References}

Abbasi, M., Abedini, M. J., Zakeri, B., \& Ghodrati Amiri, G. (2016). Seismic vulnerability assessment of a Californian multi-frame curved concrete box girder viaduct using fragility curves. Structure and Infrastructure Engineering, 12(12), 1585-1601.

Amjadian, M., \& Agrawal, A. K. (2016). Rigid-body motion of horizontally curved bridges subjected to earthquake-induced pounding. Journal of Bridge Engineering, 21(12), 04016090.

Angelidakis, V., Kardoutsou, V., Psycharis, I., \& Taflampas, I. (2017). Investigation of the effect of directivity pulses on the seismic response of a curved RC bridge. Procedia engineering, 199, 2985-2990.

Ates, S., \& Constantinou, M. C. (2011). Example of application of response spectrum analysis for seismically isolated curved bridges including soil-foundation effects. Soil Dynamics and Earthquake Engineering, 31(4), 648-661.

Baker, J. W. (2007). Quantitative classification of near-fault ground motions using wavelet analysis. Bulletin of the Seism logical Society of America, 97(5), 1486-1501.

Code, I. S. (2014). Iranian code of practice for seismic resistant design of buildings. Standard No. 2800) 4 th Edition. Road, Housing and Urban Development Research Center.BHRC-PN S-253; Tehran.Iran.

CSI Bridge (2015). INTEGRATED 3-D BRIDGE ANALYSIS, DESIGN AND RATING. https://www.csiamerica.com/products/csibridge

Desantiago, E., Mohammadi, J., \& Albaijat, H. M. (2005). Analysis of horizontally curved bridges using simple finite-element models. Practice Periodical on Structural Design and Construction, 10(1), 18-21.

Gao, K., Yuan, W., Cao, S., \& Pang, Y. (2015). Seismic performance of cable-sliding modular expansion joints subject to nearfault ground motion. Latin American Journal of Solids and Structures, 12(7), 1397-1414.

Ghosh, G., Kumar, A., Verma, N. K., \& Rai, H. (2012). Seismic Response of a Curved Bridge with Isolation Bearings. 15WCEE LISBOA.

Gimenez, J. L., Himeno, T., Shinmyo, H., \& Hayashikawa, T. (2015, August). Seismic response of bridges with sliding and elastomeric isolation bearings. In IABSE-JSCE Joint Conference on Advances in Bridge Engineering-III.

Hall, J. F., Heaton, T. H., Halling, M. W., \& Wald, D. J. (1995). Near-source ground motion and its effects on flexible buildings. Earthquake spectra, 11(4), 569-605.

Han, Q., Du, X., Liu, J., Li, Z., Li, L., \& Zhao, J. (2009). Seismic damage of highway bridges during the 2008 Wenchuan earthquake. Earthquake Engineering and Engineering Vibration, 8(2), 263-273. 
Hosoda, N., Kaneko, I., \& Kuroda, K. (1992, April). Seismic response of curved continuous Menshin bridge. In Japan Workshop on Earthquake Protective Systems for Bridges, 1 (pp. 457-67). US National Center for Earthquake Engineering Research (NCEER).

Jangid, R. S. (2005). Optimum friction pendulum system for near-fault motions. Engineering Structures, 27(3), $349-359$.

Javier López Giménez, Toshiro Hayashikawa, Takashi Matsumoto, Xingwen He, Carlos Méndez Galindo. (2011). Effect of Different Base Isolation Bearings on Nonlinear Seismic Response of Curved Viaducts. Annual Conference of Japan Society for Civil Engineers, Hokkaido.

Kalkan, E., \& Kunnath, S. K. (2006). Effects of fling step and forward directivity on seismic response of buildings. Earthquake spectra, 22(2), 367-390.

Kataria, N. P., \& Jangid, R. S. (2016). Seismic protection of the horizontally curved bridge with semi-active variable stiffness damper and isolation system. Advances in Structural Engineering, 19(7), 1103-1117.

Mazzoni, S., McKenna, F., Scott, M. H., \& Fenves, G. L . (2008). “Open system for earthquake engineering simulation (OpenSees), Version 2.5.0" Pacific Earthquake Engineering Research Center, Univ. of California, Berkeley, CA.

Mendez, C., \& Hayashikawa, T. (2009, January). Earthquake Damage Mitigation of Seismically Isolated Curved Viaducts. In IABSE Symposium Report (Vol. 96, No. 12, pp. 1-10). International Association for Bridge and Structural Engineering.

OpenSees Software, The Open System for Earthquake Engineering Simulation. (2016). Pacific Earthquake Engineering Research Center., http://OpenSees.Berkeley.edu.

Padgett, J. E., \& DesRoches, R. (2008). Methodology for the development of analytical fragility curves for retrofitted bridges. Earthquake Engineering \& Structural Dynamics, 37(8), 1157-1174.

Pahlavan, H., Zakeri, B., Amiri, G. G., \& Shaianfar, M. (2015). Probabilistic vulnerability assessment of horizontally curved multiframe RC box-girder highway bridges. Journal of Performance of Constructed Facilities, 30(3), 04015038.

Seo, J., \& Linzell, D. G. (2013). Use of response surface metamodels to generate system level fragilities for existing curved steel bridges. Engineering Structures, 52, 642-653.

Soberón, M. G., \& Soberón, J. G. (2017). Dynamic properties variation by irregular superstructure and substructure com mon bridges. Procedia Engineering, 199, 2961-2966.

Somerville, P. G. (1998). Development of an improved representation of near fault ground motions. In SMIP98 Seminar on Utilization of Strong-Motion Data (Vol. 15).

Somerville, P. G. (2002). Characterizing near fault ground motion for the design and evaluation of bridges. In Third National Conference and Workshop on Bridges and Highways. Portland, Oregon.

Tondini, N., \& Stojadinovic, B. (2012). Probabilistic seismic demand model for curved reinforced concrete bridges. Bulletin of earthquake engineering, 10(5), 1455-1479. 